\title{
Effect of Diabetes Mellitus Type 1 Diagnosis on the Corneal Cell Densities and Nerve Fibers
}

\author{
M. ČESKÁ BURDOVÁ ${ }^{1,2}$, M. KULICH ${ }^{3}$, D. DOTŘELOVÁ ${ }^{1}$, G. MAHELKOVÁ \\ ${ }^{1}$ Department of Ophthalmology, Second Faculty of Medicine, Charles University and Motol \\ University Hospital, Prague, Czech Republic, ${ }^{2}$ Department of Physiology, Second Faculty of \\ Medicine, Charles University, Prague, Czech Republic, ${ }^{3}$ Department of Probability and \\ Mathematical Statistics, Faculty of Mathematics and Physics, Charles University, Prague, \\ Czech Republic
}

Received February 28, 2018

Accepted June 6, 2018

On-line September 11, 2018

\section{Summary}

Relation of diabetes mellitus (DM) to the various stages of corneal nerve fiber damage is well accepted. A possible association between changes in the cornea of diabetic patients and diabetic retinopathy (DR), DM duration, and age at the time of DM diagnosis were evaluated. The study included 60 patients with DM type 1 (DM1) and 20 healthy control subjects. The density of basal epithelial cells, keratocytes and endothelial cells, and the status of the subbasal nerve fibers were evaluated using in vivo corneal confocal microscopy. Basal epithelial cell density increased with age $(p=0.026)$, while stromal and endothelial cell density decreased with age $(p=0.003, p=0.0005, p<0.0001)$. After the DM1 diagnosis was established, this association with age weaken. We showed nerve fiber damage in DM1 patients $(p<0.0001)$. The damage correlated with the degree of DR. DM1 patients with higher age at DM1 diagnosis had a higher nerve fiber density $(p=0.0021)$. These results indicated that age at DM1 diagnosis potentially has an important effect on final nerve fiber and corneal cell density.

\section{Key words}

Corneal nerve fibers - Diabetic neuropathy - Corneal confocal microscopy $\bullet$ Diabetic retinopathy $\bullet$ Age at diagnosis

\section{Corresponding author}

G. Mahelková, Department of Ophthalmology for Children and Adults, Second Faculty of Medicine, Charles University and Motol University Hospital, V Úvalu 84, 15600 Prague 5, Czech Republic. Fax: $+420224 \quad 432$ 720. E-mail: gabriela.mahelkova@ Ifmotol.cuni.cz; gabriela.mahelkova@fnmotol.cz

\section{Introduction}

Diabetes mellitus is a metabolic disease of great interest to clinicians and researchers due to its associated complications (Gubitosi-Klug 2014, Threatt et al. 2013, Lutty 2013).

In vivo corneal confocal microscopy is a novel diagnostic technique that provides non-invasive optical sections of corneal tissue and allows high-magnification imaging of different corneal layers including nerve fibers (Patel and McGhee 2009, Patel et al. 2009, De Cilla et al. 2009). Studies conducted over the past decade have sought to exploit this method for assessing nerve damage. Studies in diabetic patients have shown a decrease in corneal nerve fibers density, length, number of nerve branches, number of cross points, and an increase of nerve fiber tortuosity in diabetic patients. The changes correlated with the presence or absence of diabetic neuropathy (Jiang et al. 2016, Pritchard et al. 2014, Ahmed et al. 2012, Tavakoli et al. 2013, Papanas and Ziegler 2015). A possible correlation between corneal nerve fiber damage and the presence of retinopathy has also been tested in diabetic patients and more severe damage was proved in patients with retinopathy (De Cilla et al. 2009, Nitoda et al. 2012, Zhivov et al. 2013, Messmer et al. 2010). Few authors have studied possible correlations between the mentioned corneal changes and the degree of diabetic retinopathy.

Other studies have also looked at changes in cell 
density, between diabetic patients and healthy individuals, within different corneal layers. Diabetic keratopathy has been shown to be associated with a thinner epithelium, decreased basal epithelial and endothelial cell density, and decreased density of keratocytes (Rosenberg et al. 2000, Quadrado et al. 2006, Szalai et al. 2016, Dehghani et al. 2016).

We tested the differences in epithelial, stromal, and endothelial cell density, and corneal nerve fiber damage between a group of patients with type 1 diabetes (DM1) and a group of healthy individuals. We also tested possible associations between changes in diabetic patients and the degree of diabetic retinopathy, DM duration, and age at the time of DM1 diagnosis.

\section{Materials and Methods}

\section{Study subjects}

The prospective observational study included 60 patients with diabetes mellitus type 1 (29 male, 31 female) and 20 age-matched control subjects (9 male, 11 female). Patients were recruited from the Department of Ophthalmology for children and adults, Second Faculty of Medicine, Charles University, and Motol University Hospital. Consecutive patients who met the criteria and agreed to cooperate were included in the study. All the patients were sent to our ophthalmology department for regular control and screening for diabetic retinopathy by their diabetologist. The data about the diagnosis statement, the age at diagnosis, and $\mathrm{HbA} 1 \mathrm{c}$ values were taken from their medical chart. The last HbAlc value was recorded. Volunteers without history of diabetes (mostly from the staff of the clinic) were taken as control subjects. Subjects were excluded if they wore or had previously worn contact lens, had a history of chronic topical medication, corneal disease, glaucoma, active or chronic anterior segment disease, or suffered from any systemic disease, other than diabetes, known to affect corneal subbasal innervation. Also, the patients who had received intraocular surgery or laser treatments were excluded.

Informed consent was obtained from each patient after an explanation of the nature and possible consequences of the study. The study was approved by the Motol University Hospital Ethics Committee. The study protocol followed the tenets of the Declaration of Helsinki for research involving human participants.

\section{Evaluation of retinal status}

The diabetic patients were subdivided, based on a fundus examination (using biomicroscopy and fundus photography) and need of therapy intervention, into three groups: 1) without retinopathy, 2) mild retinopathy, and 3) severe retinopathy. Patients with no signs of retinopathy were included in the "no DR" group, patients with mild or moderate non-proliferative retinopathy (NPDR), according to the Early Treatment of Diabetic Retinopathy Study (ETDRS) (Wilkinson et al. 2003, Utsunomiya et al. 2015) were assigned to the "mild DR" group, and patients with severe NPDR or proliferative retinopathy $(\mathrm{PDR})$ were placed in the "severe DR" group.

\section{In vivo corneal confocal microscopy}

In vivo confocal microscopy (IVCM) images of the cornea were obtained from all participants. Topical anesthesia (oxybuprocaine hydrochloride $0.4 \%$ ) was used before IVCM examinations. A corneal confocal microscope (scanning slit corneal microscope (SSCM), Confoscan 3.0, NIDEK Technologies, Italy), equipped with a non-applanating 40x immersion objective lens, designed for full-thickness examination of the cornea, with a working distance of $1.92 \mathrm{~mm}$ (Achroplan, Zeiss, Oberkochen, Germany), was used to scan the central corneal region. Prior to use, the objective lens of the confocal microscope was disinfected (isopropyl alcohol $70 \% \mathrm{vol} / \mathrm{vol}$, swabs), and one drop of viscous isotonic gel (Vidisic gel, Bausch and Lomb, Rochester, NY, USA) was applied to the tip of the lens. Images of the patient's central cornea in full thickness, starting at the endothelium layer, were recorded. The image interval was set to $5 \mu \mathrm{m}$. The automatic or semi-automatic scanning mode was used. During scanning, typically at least two scanning cycles were performed, and at least 700 images of the cornea of each eye were captured and both eyes were scanned.

\section{Analysis of corneal images}

The cell density of 1) basal epithelial cells, 2) keratocytes in the anterior and posterior stroma, and 3) endothelial cells were evaluated using analysis software provided with the instrument. The manual cell-count processing mode was used. Two representative images (one from each eye) of basal epithelial cells, and endothelial cells were used for cell density evaluation. Recommendations from the software provider were followed for cell counts: for endothelial cells at least 
35 cells were counted (polygon area about $0.02 \mathrm{~mm}^{2}$ ) and for basal epithelial cells, about 70 cells were counted (polygon area about $0.010 \mathrm{~mm}^{2}$ ). The average number of nuclei of all keratocytes in a fixed area $0.080 \mathrm{~mm}^{2}$ was calculated in the two images following the last frame of the endothelium (for posterior keratocyte density), and the average number of nuclei of all keratocytes on the two frames before the images of the epithelium (for anterior keratocytes). The mean value obtained from the evaluated images was recorded as the cell density in the particular layer and was expressed as cells $/ \mathrm{mm}^{2}$.

Manual identification of nerve fibers and branching, and manual tracing of nerve fibers were used. Customize image analysis software (NIS-Elements, Laboratory Imaging, Czech Republic) was used for nerve fiber analysis. Since the Confoscan 3 produces images with blurred edges, these were removed and only the well-focused central area of $0.1 \mathrm{~mm}^{2}$ was used for nerve fiber assessment. Four of the most representative images (two from each eye with the best captured nerve fibers) (Smith et al. 2013) were selected for nerve fiber measurements, and the values of the total nerve fiber length (NFL, in $\mathrm{mm}$ per $\mathrm{mm}^{2}$ ), density (number) of main nerves fibers (NFD, per $\mathrm{mm}^{2}$ ), density of all nerve fibers (t-NFD, per $\mathrm{mm}^{2}$ ), density of branch cross points $\left(\mathrm{NBD}\right.$, per $\mathrm{mm}^{2}$ ), and nerve fiber tortuosity (NFL, a dimensionless index) were determined. To avoid a subjective evaluation of nerve fiber tortuosity, the methods suggested by Heneghan et al. (2002), for retinal vessels, were used to determine nerve fiber tortuosity. This was done by calculating the ratio of the shortest distance between nerve fiber ends and the real length of the fiber.

All the images were evaluated by one investigator (G. M.), without the investigator knowing the identity of the patient.

\section{Statistical analysis}

Comparisons of age, DM1 duration, and HbA1c between groups of subjects were performed by a classic one-way ANOVA. Effects of age, DM1 duration, HbA1c, DM1 status, and DR group were estimated and tested using (generalized estimating equation) GEE models, where two or four measurements, of a given outcome, on both eyes of a single subject were treated as a multivariate observation. GEE models were fitted with a working independence structure and sandwich estimators were used to adjust variance to correlated outcomes. Reported p-values and confidence intervals were obtained using Wald-type statistics. The first, unadjusted univariate models were fit using the whole sample $(\mathrm{n}=80)$, with linear age, DM1 status, and DR group (nested within DM1 patients) included separately as individual predictors. Next, adjusted models were fit using DM1 patients $(\mathrm{n}=60)$ with age at DM1 diagnosis, duration of DM1, HbAlc, and DR group included concurrently and adjusted for each other. Library 'gee' in the statistical package R 3.3.0 was used to conduct the analyses.

\section{Results}

The clinical and demographic characteristics of the groups are presented in Table 1. The mean age of the subjects did not differ between the groups $(p=0.36)$. The duration of DM was significantly longer in patients with severe diabetic retinopathy (mean 24.0 years) and mild retinopathy (mean 20.4 years) compared to patients without retinopathy (mean 13.5 years; $p$-value for difference $=0.0004$ ). HbAlc did not differ between the three groups of diabetic patients $(\mathrm{p}=0.83)$. The cell densities of the individual corneal layers are presented in Table 2.

Table 1. Characteristics of the groups.

\begin{tabular}{lccccc}
\hline Group & $\mathbf{n}$ & Age & Duration of DM & Age at DM1 diag. & HbA1c \\
\hline Healthy & 20 & $32.2 \pm 9.9$ & - & - & - \\
TIDM, without DR & 24 & $37.7 \pm 12.3$ & $13.5 \pm 7.2$ & $24.2 \pm 12.8$ & $70.8 \pm 16.0$ \\
TIDM, mild DR & 21 & $35.9 \pm 11.1$ & $20.4 \pm 9.1$ & $15.5 \pm 12.8$ & $73.3 \pm 11.2$ \\
TIDM, severe DR & 15 & $33.6 \pm 7.7$ & $24.0 \pm 7.3$ & $9.6 \pm 3.2$ & $71.6 \pm 13.4$ \\
& & $\mathrm{p}=0.36$ & $\mathrm{p}=0.0004$ & $\mathrm{p}=0.0007$ & $\mathrm{p}=0.83$ \\
\hline
\end{tabular}

Data are mean $\pm \mathrm{SD}$. 
Table 2. Densities of cells in individual corneal layers and subbasal nerve fiber parameters (descriptive statistics).

\begin{tabular}{|c|c|c|c|c|}
\hline & $\begin{array}{c}\text { Healthy } \\
(n=20)\end{array}$ & $\begin{array}{c}\text { T1DM, } \\
\text { without DR } \\
(n=24)\end{array}$ & $\begin{array}{c}\text { T1DM, } \\
\text { mild DR } \\
(n=21)\end{array}$ & $\begin{array}{c}\text { T1DM, } \\
\text { severe DR } \\
(n=15)\end{array}$ \\
\hline Basal epithelial cell density (cells/mm²) & $6464.2 \pm 522.4$ & $6759.4 \pm 558.3$ & $6534.4 \pm 446.4$ & $6566.2 \pm 576.5$ \\
\hline Anterior stroma cell density (cells $/ \mathrm{mm}^{2}$ ) & $782.3 \pm 134.1$ & $659.8 \pm 180.1$ & $712.7 \pm 147.9$ & $711.8 \pm 110.4$ \\
\hline Posterior stroma cell density (cells $/ \mathrm{mm}^{2}$ ) & $534.4 \pm 56.1$ & $500.4 \pm 63.0$ & $536.0 \pm 56.2$ & $532.7 \pm 48.5$ \\
\hline Endothelial cell density (cells $/ \mathrm{mm}^{2}$ ) & $2927.4 \pm 398.0$ & $2701.8 \pm 479.4$ & $2779.8 \pm 272.9$ & $2925.2 \pm 344.0$ \\
\hline Nerve fiber density $\left(\mathrm{No} / \mathrm{mm}^{2}\right)$ & $43.12 \pm 7.20$ & $31.98 \pm 9.30$ & $31.31 \pm 7.19$ & $19.33 \pm 8.04$ \\
\hline Total nerve fiber density $\left(\mathrm{No} / \mathrm{mm}^{2}\right)$ & $69.50 \pm 16.93$ & $55.73 \pm 19.77$ & $51.55 \pm 14.84$ & $32.67 \pm 14.95$ \\
\hline Nerve fiber length $\left(\mathrm{mm} / \mathrm{mm}^{2}\right)$ & $16.45 \pm 3.40$ & $12.37 \pm 4.23$ & $11.98 \pm 2.98$ & $7.50 \pm 3.29$ \\
\hline Nerve fiber tortuosity & $1.08 \pm 0.01$ & $1.08 \pm 0.01$ & $1.09 \pm 0.02$ & $1.12 \pm 0.05$ \\
\hline Density of branch cross points $\left(\mathrm{No} / \mathrm{mm}^{2}\right)$ & $30.38 \pm 18.82$ & $21.15 \pm 12.42$ & $19.29 \pm 11.89$ & $10.06 \pm 7.36$ \\
\hline
\end{tabular}

Data are mean \pm SD.

Densities of corneal cells all changed with age (Table 3). The basal epithelial cell density increased by 116 cells $/ \mathrm{mm}^{2}$ every 10 years of age $(95 \% \mathrm{CI}$ $14-219$ cells $\left./ \mathrm{mm}^{2} ; \mathrm{p}=0.026\right)$. Stroma cell densities and endothelial cell density all decreased with age: anterior stroma cell density decreased by 55 cells $/ \mathrm{mm}^{2}$ every 10 years $\quad\left(95 \% \mathrm{CI}\right.$ for decrease $17-94 \mathrm{cells} / \mathrm{mm}^{2}$; $\mathrm{p}=0.005$ ), posterior stroma cell density decreased by 20 cells $/ \mathrm{mm}^{2}$ every 10 years $(95 \% \mathrm{CI}$ for decrease 9-30 cells $/ \mathrm{mm}^{2} ; \mathrm{p}=0.0003$ ), and endothelial cell density decreased by 163 cells $/ \mathrm{mm}^{2}$ every 10 years $(95 \%$ CI for decrease 90-237 cells $\left./ \mathrm{mm}^{2} ; \mathrm{p}<0.0001\right)$. Among DM1 patients, these age effects were mainly driven by age at DM1 diagnosis and did not depend on the duration of the disease (Table 4). After the DM1 diagnosis was established, the association of age with basal epithelial cell density becomes negligible and the associations of age with other cell densities weaken and became nonsignificant. None of these cell densities were associated with DM status except anterior stroma cell density, which was lower by 92 cells $/ \mathrm{mm}^{2}$ in DM1 subjects than in healthy controls $(95 \% \mathrm{CI}$ for the difference $23-161$ cells $\left./ \mathrm{mm}^{2} ; \mathrm{p}=0.009\right)$. The largest decrease in anterior stroma cell density was observed among DM1 patients with no diabetic retinopathy (122 cells $/ \mathrm{mm}^{2}$ lower than in healthy controls, $95 \% \mathrm{CI}$ $32-213$ cells $\left./ \mathrm{mm}^{2} ; \mathrm{p}=0.008\right)$. There was no association between the density of the cells in a particular corneal layer and $\mathrm{HbA} 1 \mathrm{c}$ or the degree of diabetic retinopathy (Table 4).

Characteristics of subbasal nerve fiber parameters are presented in Table 2. We found no associations between age and NFD, t-NFD, NBD, NFL, or NFT (Table 3). The NFD, t-NFD, NBD and NFL were all significantly lower in DM1 patients than in controls $(\mathrm{p}<0.0001$, Table 3$)$ and seemed to further decrease with the degree of DR. Among DM1 patients, the NFD, t-NFD, NBD, and NFL did not differ between "no DR" and "mild DR" but were significantly lower in "severe DR" compared to "no DR" $(p=0.0012, p=0.0010$, $p=0.0194, p=0.0079$, resp., Table 4, Fig. 1).

NFT was higher in "mild DR" and "severe DR" than in controls $(p=0.0077, p=0.0024$, resp., Table 3$)$. Among DM1 patients, NFT was higher in "mild DR" and "severe DR" compared to "no DR" ( $p=0.0394, p=0.0155$, resp., Table 4). DM1 patients with higher ages at the time of DM1 diagnosis had higher NFDs compared to DM1 patients of the same age and degree of DR who had an earlier diagnosis $(p=0.0021)$. A similar situation was seen with regard to NFL ( $p=0.0540$, Table 4$)$. There were no associations between nerve fiber parameters and HbA1c or the duration of DM1 (Table 4).

\section{Discussion}

Diabetes mellitus is a chronic systemic disorder. Its association with the different stages of keratopathy is well accepted and estimated to developed in up to two-thirds of patients (Shih et al. 2017, Threatt et al. 2013).

We found that the density of basal epithelial cells increased with age. Previous studies failed to find a significant correlation between basal epithelial cell density and age (Gambato et al. 2015, Niederer et al. 


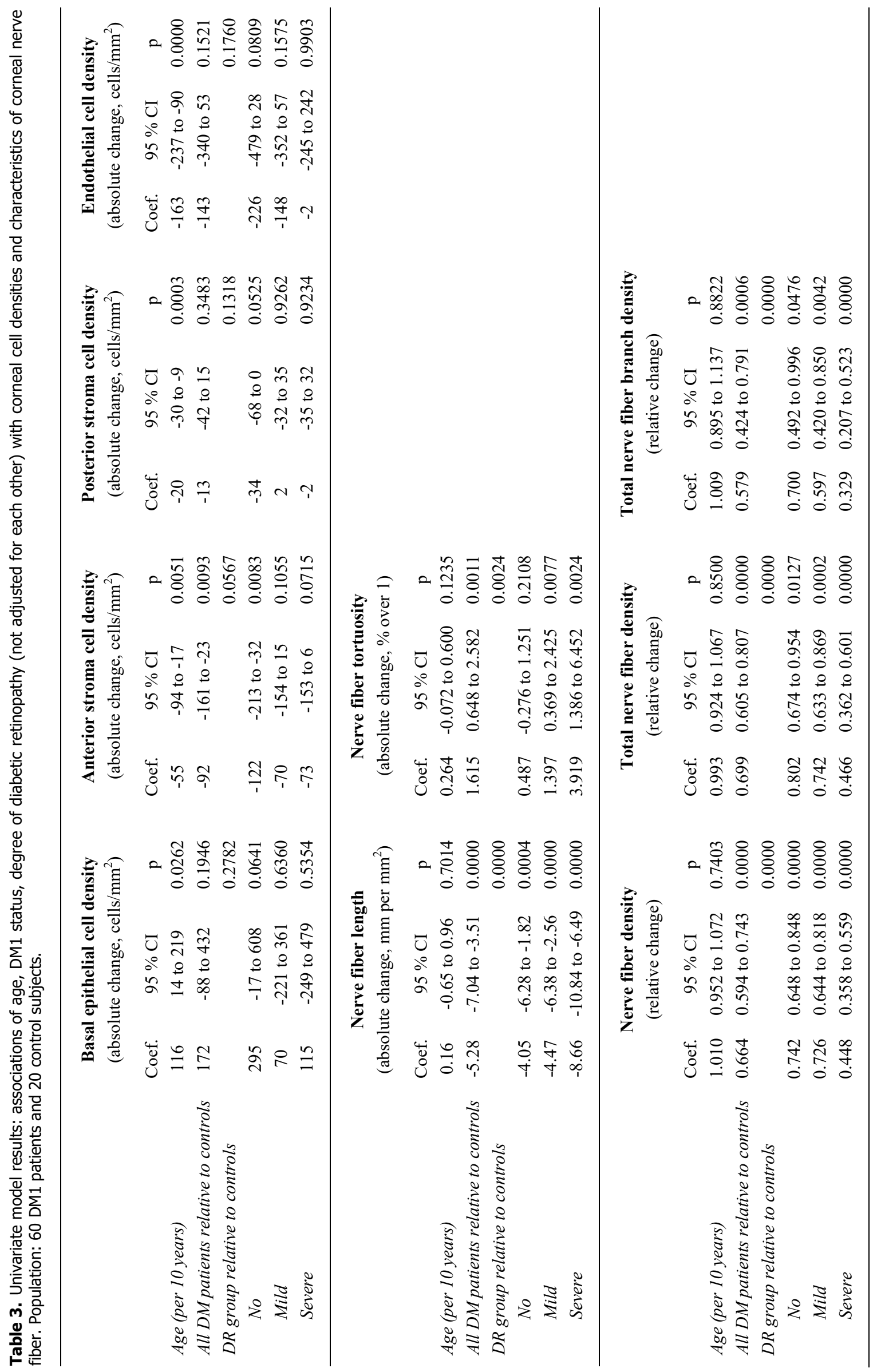




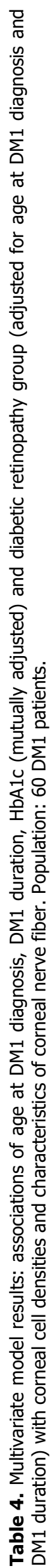
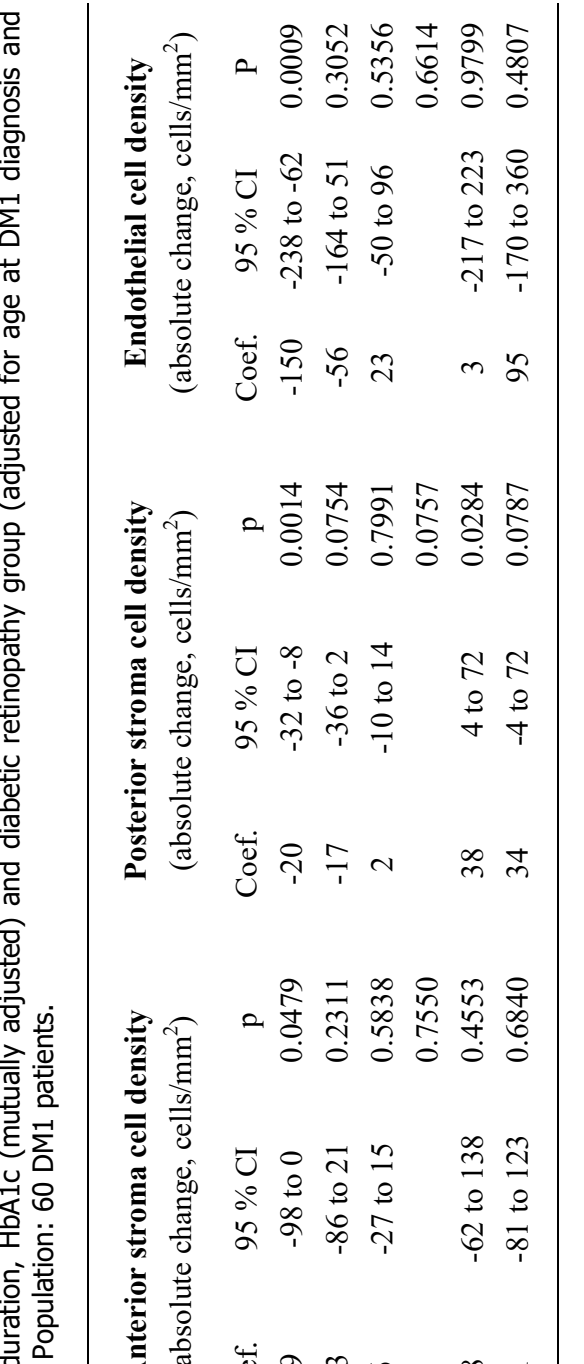

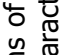

.

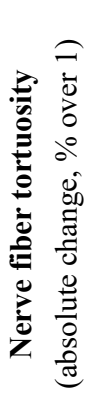

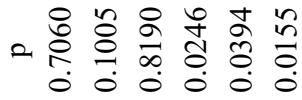

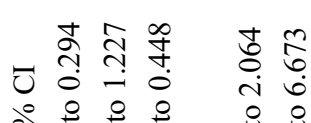

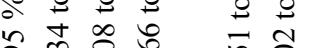

๙2.

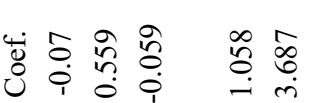

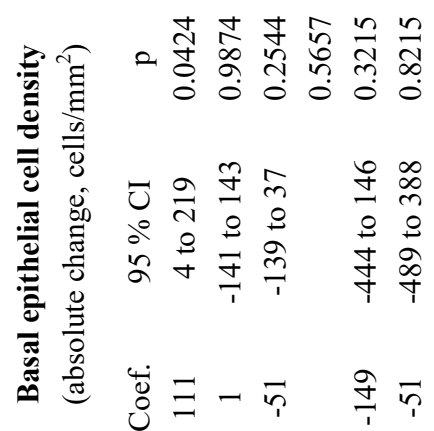

言

$\stackrel{2}{2} \approx$

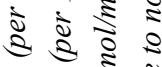

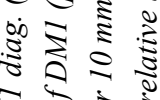

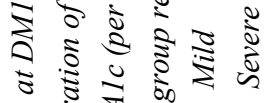

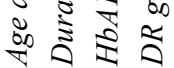

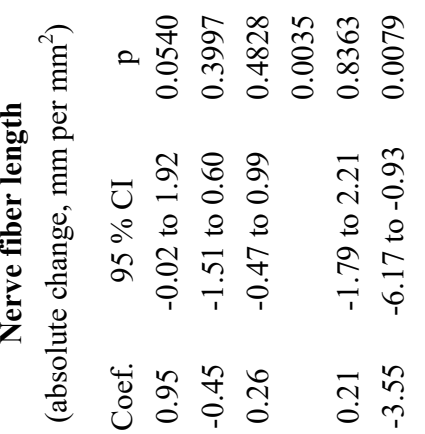

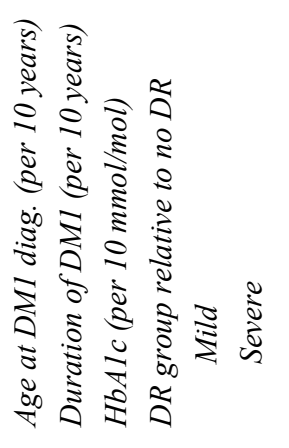

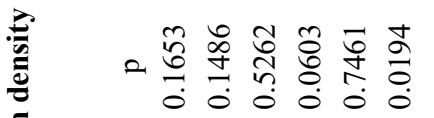

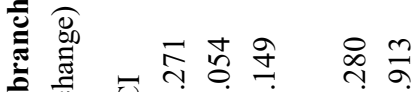

걱

$\therefore \circ \div \div$

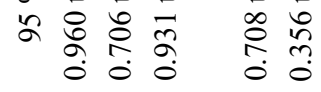

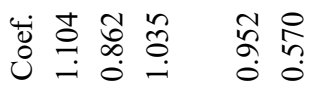

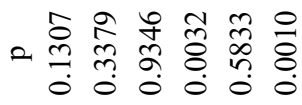

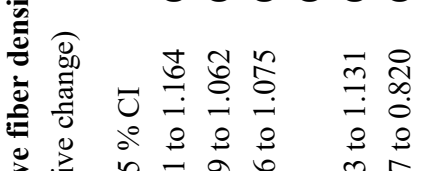

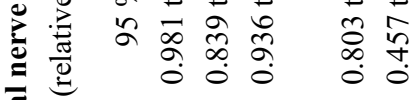

है

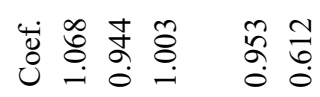

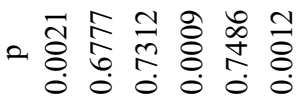

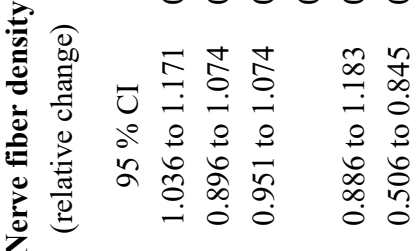

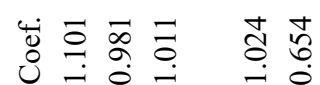

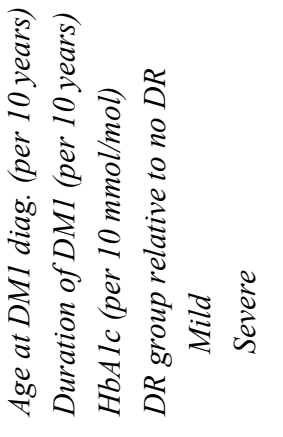


Nerve fiber density

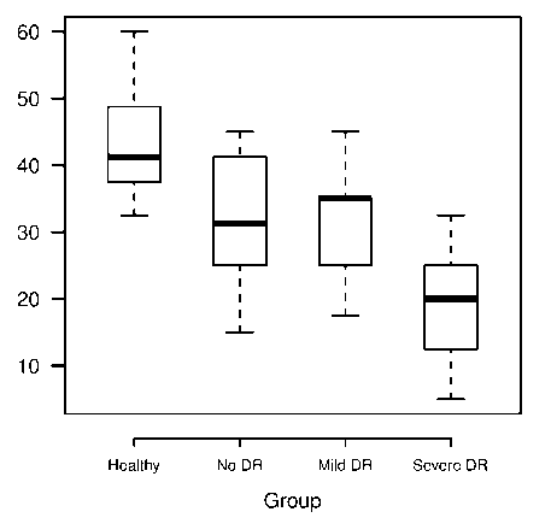

Nerve fiber length

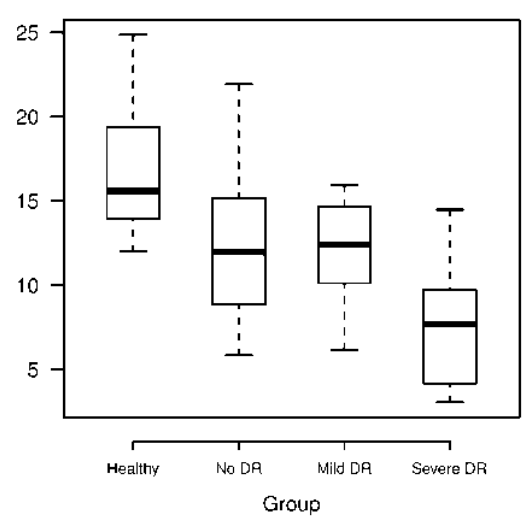

Total nerve fiber branch density

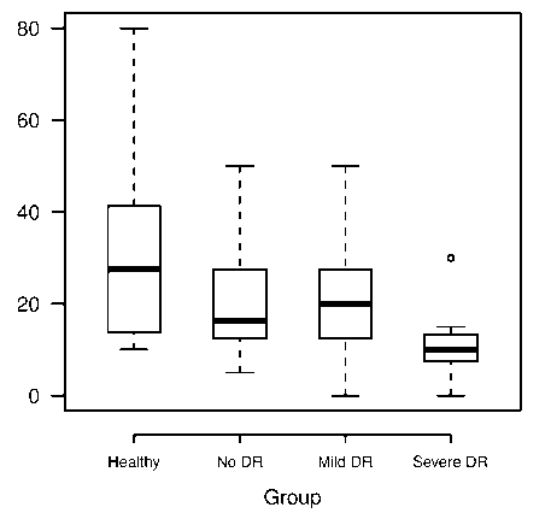

2007, Vanathi et al. 2003), although there was a trend in a study by Niederer et al. (2007) and Vantahi et al. (2003). However, according to our results, the association with age disappeared after the DM1 diagnosis was established, which may indicate the opposite influence of DM1 on epithelial cell density.

Although we did not find differences in epithelial cell density in DM1 patients compared to healthy controls, some of the previous studies found a decrease of basal epithelial cell density in DM patients
Fig. 1. Nerve fiber density (NFD; $\mathrm{No} / \mathrm{mm}^{2}$ ), total nerve fiber density $\left(\mathrm{t}-\mathrm{NFD} ; \mathrm{No} / \mathrm{mm}^{2}\right)$, nerve fiber length (NFL; $\mathrm{mm} / \mathrm{mm}^{2}$ ) and tortuosity (NFT; dimensionless index), and total nerve fiber branch density (NFD; No/mm ${ }^{2}$ ) in healthy control subjects (Healthy) and patients with type 1 diabetes mellitus classified according to the degree of diabetic retinopathy (No DR, Mild DR, Severe DR).

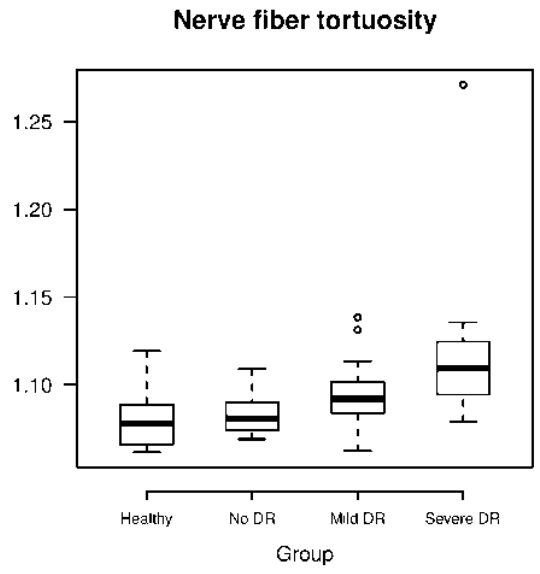


Decreased epithelial cell density has also been demonstrated in the streptozotocin-induced diabetic mouse model (Cai et al. 2014). However, there was more than a $200 \%$ increase in the serum glucose level of STZ-treated mice.

An increase in insulin-like growth factor binding protein 3 (IGFBP3) has been reported in the tears of diabetic patients ( $\mathrm{Wu}$ et al. 2012). IGFBP3 belongs to a family of high affinity insulin-like growth factor (IGF) binding proteins, which function to sequester extracellular IGF-1 and prevent activation of IGF-1 (insulin-like growth factor) receptors (Baxter 2000). IGFBP 3 has also been shown to regulate insulin resistance and apoptosis in a variety of cell types via IGF-1 independent pathways (Muzumdar et al. 2006, Jia et al. 2010). It has been suggested that prolonged elevated IGFBP 3 expression may contribute to the pathogenesis of corneal epithelial abnormalities in diabetic patients through attenuation of the normal IGF-1 signaling pathway. However, in some studies the increase in IGFBP3 was not found to be significant in DM1 patients, possibly due to the confounding effects associated with insulin treatment (Song et al. 2016, Wu et al. 2012). It was recently shown that treatment with insulin restores the circadian rhythm of dividing corneal epithelial cells in diabetic mice (Song et al. 2016). Insulin treatment may be another reason why we did not observed a decrease in basal epithelial cell density in diabetic patients compared to healthy subjects (Klocek et al. 2009).

Results regarding the effect of DM on keratocyte density are inconsistent. Some authors have found no difference in the keratocyte density between DM2 or DM1 and control subjects (Quadrado et al. 2006, Dehghani et al. 2016). Szalai et al. (2016) found a higher keratocyte density in patients with DM1 without diabetic retinopathy compared to the controls. We found lower keratocyte density in the anterior stroma of diabetic patients (most expressed in the "no DR" group) compared to control subjects, with no differences in posterior stroma keratocyte density in diabetic patients compared to healthy subjects. Our results are in accordance with a recent study by Bitirgen et al. (2014), who also found a decreased density of keratocytes in the anterior stroma in DM2 patients, but no difference in keratocyte density in the posterior stroma relative to control subjects. However, unlike their results, we found the highest decrease in anterior keratocyte density in DM1 patients with no DR. However, the mean age of the patients with no DR was the highest. In accordance with previous studies (Dehghani et al. 2016, Gambato et al. 2015, Niederer et al. 2007), both the anterior and posterior stroma cell density decreased with age. Thus, the lower keratocyte density within the no DR group may represent bias, only. Again, after the DM1 diagnosis was established, the association with age weaken. Thus, this may again suggest that DM1 (and/or insulin treatment) has some effect on the regulation of these cells.

Studies have demonstrated that diabetic patients have altered endothelial barrier function, greater polymegathism and pleiomorphism of endothelial cells, and lower endothelial cell density relative to age-matched healthy controls (Inoue et al. 2002, Calvo-Maroto et al. 2015, Sudhir et al. 2012, Szalai et al. 2016). Others have found lower endothelial cell density only in patients with type 2 diabetes and proliferative diabetic retinopathy (Bitirgen et al. 2014). An association between HbA1c and grade of DR has also been found (Sudhir et al. 2012, Modis et al. 2010). In this study we confirmed the wellknown effect of age on endothelial cells density (Gambato et al. 2015, Niederer et al. 2007), but we did not find any difference in endothelial cell density in DM1 patients compared to healthy subjects. However, the effect of age on endothelial cell density seemed to weaken after a diabetes diagnosis was established, the same was seen for keratocyte density. Thus, this effect should be further evaluated in future studies.

We did not find any connection between diabetes duration, HbA1c values, and diabetic retinopathy status and cell density of any particular corneal layer.

Several studies have shown that diabetes mellitus effects the status of corneal subbasal nerve fibers (Papanas and Ziegler 2015, Jiang et al. 2016). However, comparing results from different studies is complicated because of differences in methodology as well as the use of different corneal confocal microscopy devices. Values obtained using different types of devices are not directly comparable and the mean value of NFD and NFL can vary (Erie et al. 2008, Szaflik et al. 2007). Generally, NFD values (usually defined as the density of main nerve fibers) are higher when using the slit scanning microscopy system (SSCM) compared to the laser scanning microscopy system (LSCM) (Tavakoli et al. 2015, Petropoulos et al. 2015). The lower resolution of SSCM may explain the difficulty in recognizing the main fibers and, as such, explain the overestimation. We also evaluated the total number of nerve fibers but it did not appear to provide any useful information. In contrast to NFD, NFL values are often lower when using the SSCM (Tavakoli et al. 2012, 
Petropoulos et al. 2015, Jiang et al. 2016).

There is disagreement regarding the effect of age on corneal nerve density (Oliveira-Soto and Efron 2001, Patel et al. 2009, Erie et al. 2005). We did not find any effect of age on nerve fiber status in our study. However, in our study the patients were young adults between 22-49 years of age. According to earlier studies, significant corneal nerve density reduction occurred at elderly ages mainly (70 years or older) (He et al. 2010, Reichard et al. 2014). This fact explains our results.

As seen in previous studies, we observed that decreased NFD, t-NFD, NBD and NFL in diabetic patients (both with and without DR) compared with healthy subjects (Tavakoli et al. 2012, Messmer et al. 2010, Tavakoli et al. 2010, Chang et al. 2006, Papanas and Ziegler 2015). Additionally, we demonstrated that damage to nerve fibers was more pronounced in patients with severe DR than in patients without DR.

NFT (the degree of twistedness of corneal nerves) has been widely tested to describe changes in corneal subbasal nerves. Unfortunately, there is no standard definition for tortuosity and no unified approach for its evaluation (Lagali et al. 2015). We used a method described by Heneghan et al. (2002) that was used for evaluation of retinal vessels tortuosity. In agreement with previous studies, we found higher NFT in DM1 patients compared to healthy controls. Previous studies have demonstrated a possible correlation between NFT and DR (Chang et al. 2006, Lagali et al. 2015, Nitoda et al. 2012). We found that tortuosity increased with the degree of DR.

DN (as well as DR) is no longer regarded as a purely vascular pathology. Instead, there is strong evidence that diabetes causes apoptosis of both neural and vascular elements. Thus, there is good reason to define diabetic neuropathy and retinopathy as a form of chronic neurovascular degeneration (Barber et al. 2011, Zochodne 2015, Shih et al. 2017). From this point of view, the association between subbasal nerve fiber damage and degree of DR observed in our study was not surprising.

We did not find any relationship between DM duration (when adjusting for DR) or HbAlc values and nerve fibers parameters. A new and important finding from our study was the possible relationship between age at the time DM1 diagnosis and nerve fiber status. The adverse effects of DM1 on NFD seemed to be more pronounced in patients diagnosed at an earlier age. This may indicate a greater sensitivity among younger individuals to permanent nerve fiber damage. Davidson et al. (2012) explained this by suggesting that nerves in younger individuals are still developing. Diabetes with a younger age onset may arrest nerve development, contributing to the appearance of nerve degeneration (Davidson et al. 2012). Also, common problems with compensation and compliance in young individuals during puberty may contribute to more profound damage.

The main limitation of our study was the low resolution of the SSCM device. The LSCM system is used most often today, because the axial resolution is better using the LSCM (Villani et al. 2014). However, our results are in accordance with previous SSCM studies (Tavakoli et al. 2012, Wang et al. 2015). We also showed the effect of DM on subbasal nerve fibers, which were in accordance with the results coming from LSCM studies, although the absolute values of the parameters differed.

During the past ten years many studies have documented the potential benefits of corneal confocal microscopy for describing changes to corneal cells and nerves, in many diseases. This is especially true when monitoring changes in diabetic patients. This non-invasive and easy-to-implement method cannot only help in making a clinical diagnosis and monitoring the effect of therapy, it can also bring provide important information needed to explain the pathogenetic mechanisms associated with the well-documented changes that lead to damage.

\section{Conflict of Interest}

There is no conflict of interest.

\section{Acknowledgements}

The project was supported by MH CZ - DRO, Motol University Hospital, Prague, Czech Republic 00064203 and project CZ.2.16/3.1.00/24022.

\section{References}

AHMED A, BRIL V, ORSZAG A, PAULSON J, YEUNG E, NGO M, ORLOV S, PERKINS BA: Detection of diabetic sensorimotor polyneuropathy by corneal confocal microscopy in type 1 diabetes: a concurrent validity study. Diabetes Care 35: 821-828, 2012. 
BARBER AJ, GARDNER TW, ABCOUWER SF: The significance of vascular and neural apoptosis to the pathology of diabetic retinopathy. Invest Ophthalmol Vis Sci 52: 1156-1163, 2011.

BAXTER RC: Insulin-like growth factor (IGF)-binding proteins: interactions with IGFs and intrinsic bioactivities. Am J Physiol Endocrinol Metab 278: E967-E976, 2000.

BITIRGEN G, OZKAGNICI A, MALIK RA, KERIMOGLU H: Corneal nerve fibre damage precedes diabetic retinopathy in patients with type 2 diabetes mellitus. Diabet Med 31: 431-438, 2014.

CAI D, ZHU M, PETROLL WM, KOPPAKA V, ROBERTSON DM: The impact of type 1 diabetes mellitus on corneal epithelial nerve morphology and the corneal epithelium. Am J Pathol 184: 2662-2670, 2014.

CALVO-MAROTO AM, CERVINO A, PEREZ-CAMBRODI RJ, GARCIA-LAZARO S, SANCHIS-GIMENO JA: Quantitative corneal anatomy: evaluation of the effect of diabetes duration on the endothelial cell density and corneal thickness. Ophthalmic Physiol Opt 35: 293-298, 2015.

CHANG PY, CARREL H, HUANG JS, WANG IJ, HOU YC, CHEN WL, WANG JY, HU FR: Decreased density of corneal basal epithelium and subbasal corneal nerve bundle changes in patients with diabetic retinopathy. Am J Ophthalmol 142: 488-490, 2006.

DAVIDSON EP, COPPEY LJ, YOREK MA: Early loss of innervation of cornea epithelium in streptozotocin-induced type 1 diabetic rats: improvement with ilepatril treatment. Invest Ophthalmol Vis Sci 53: 8067-8074, 2012.

DE CILLA S, RANNO S, CARINI E, FOGAGNOLO P, CERESARA G, ORZALESI N, ROSSETTI LM: Corneal subbasal nerves changes in patients with diabetic retinopathy: an in vivo confocal study. Invest Ophthalmol Vis Sci 50: 5155-5158, 2009.

DEHGHANI C, PRITCHARD N, EDWARDS K, RUSSELL AW, MALIK RA, EFRON N: Abnormal anterior corneal morphology in diabetes observed using in vivo laser-scanning confocal microscopy. Ocul Surf 14: 507-514, 2016.

ERIE EA, MCLAREN JW, KITTLESON KM, PATEL SV, ERIE JC, BOURNE WM: Corneal subbasal nerve density: a comparison of two confocal microscopes. Eye Contact Lens 34: 322-325, 2008.

ERIE JC, MCLAREN JW, HODGE DO, BOURNE WM: The effect of age on the corneal subbasal nerve plexus. Cornea 24: 705-709, 2005.

GAMBATO C, LONGHIN E, CATANIA AG, LAZZARINI D, PARROZZANI R, MIDENA E: Aging and corneal layers: an in vivo corneal confocal microscopy study. Graefes Arch Clin Exp Ophthalmol 253: 267-275, 2015.

GUBITOSI-KLUG RA: The diabetes control and complications trial/epidemiology of diabetes interventions and complications study at 30 years: summary and future directions. Diabetes Care 37: 44-49, 2014.

HE J, BAZAN NG, BAZAN HE: Mapping the entire human corneal nerve architecture. Exp Eye Res 91: 513-523, 2010.

HENEGHAN C, FLYNN J, O'KEEFE M, CAHILL M: Characterization of changes in blood vessel width and tortuosity in retinopathy of prematurity using image analysis. Med Image Anal 6: 407-429, 2002.

INOUE K, KATO S, INOUE Y, AMANO S, OSHIKA T: The corneal endothelium and thickness in type II diabetes mellitus. Jpn J Ophthalmol 46: 65-69, 2002.

JIA Y, LEE KW, SWERDLOFF R, HWANG D, COBB LJ, SINHA HIKIM A, LUE YH, COHEN P, WANG C: Interaction of insulin-like growth factor-binding protein-3 and BAX in mitochondria promotes male germ cell apoptosis. J Biol Chem 285: 1726-1732, 2010.

JIANG MS, YUAN Y, GU ZX, ZHUANG SL: Corneal confocal microscopy for assessment of diabetic peripheral neuropathy: a meta-analysis. Br J Ophthalmol 100: 9-14, 2016.

KLOCEK MS, SASSANI JW, MCLAUGHLIN PJ, ZAGON IS: Naltrexone and insulin are independently effective but not additive in accelerating corneal epithelial healing in type I diabetic rats. Exp Eye Res 89: 686-692, 2009.

LAGALI N, POLETTI E, PATEL DV, MCGHEE CN, HAMRAH P, KHEIRKHAH A, TAVAKOLI M, PETROPOULOS IN, MALIK RA, UTHEIM TP, ZHIVOV A, STACHS O, FALKE K, PESCHEL S, GUTHOFF R, CHAO C, GOLEBIOWSKI B, STAPLETON F, RUGGERI A: Focused tortuosity definitions based on expert clinical assessment of corneal subbasal nerves. Invest Ophthalmol Vis Sci 56: 5102-5109, 2015.

LUTTY GA: Effects of diabetes on the eye. Invest Ophthalmol Vis Sci 54: ORSF81-87, 2013. 
MESSMER EM, SCHMID-TANNWALD C, ZAPP D, KAMPIK A: In vivo confocal microscopy of corneal small fiber damage in diabetes mellitus. Graefes Arch Clin Exp Ophthalmol 248: 1307-1312, 2010.

MODIS L JR, SZALAI E, KERTESZ K, KEMENY-BEKE A, KETTESY B, BERTA A: Evaluation of the corneal endothelium in patients with diabetes mellitus type I and II. Histol Histopathol 25: 1531-1537, 2010.

MUZUMDAR RH, MA X, FISHMAN S, YANG X, ATZMON G, VUGUIN P, EINSTEIN FH, HWANG D, COHEN P, BARZILAI N: Central and opposing effects of IGF-I and IGF-binding protein-3 on systemic insulin action. Diabetes 55: 2788-2796, 2006.

NIEDERER RL, PERUMAL D, SHERWIN T, MCGHEE CN: Age-related differences in the normal human cornea: a laser scanning in vivo confocal microscopy study. Br J Ophthalmol 91: 1165-1169, 2007.

NITODA E, KALLINIKOS P, PALLIKARIS A, MOSCHANDREA J, AMOIRIDIS G, GANOTAKIS ES, TSILIMBARIS M: Correlation of diabetic retinopathy and corneal neuropathy using confocal microscopy. Curr Eye Res 37: 898-906, 2012.

OLIVEIRA-SOTO L, EFRON N: Morphology of corneal nerves using confocal microscopy. Cornea 20: 374-384, 2001.

PAPANAS N, ZIEGLER D: Corneal confocal microscopy: recent progress in the evaluation of diabetic neuropathy. J Diabetes Investig 6: 381-389, 2015.

PATEL DV, MCGHEE CN: In vivo confocal microscopy of human corneal nerves in health, in ocular and systemic disease, and following corneal surgery: a review. Br J Ophthalmol 93: 853-860, 2009.

PATEL DV, TAVAKOLI M, CRAIG JP, EFRON N, MCGHEE CN: Corneal sensitivity and slit scanning in vivo confocal microscopy of the subbasal nerve plexus of the normal central and peripheral human cornea. Cornea 28: 735-740, 2009.

PETROPOULOS IN, GREEN P, CHAN AW, ALAM U, FADAVI H, MARSHALL A, ASGHAR O, EFRON N, TAVAKOLI M, MALIK RA: Corneal confocal microscopy detects neuropathy in patients with type 1 diabetes without retinopathy or microalbuminuria. PLoS One 10: e0123517, 2015.

PRITCHARD N, EDWARDS K, DEHGHANI C, FADAVI H, JEZIORSKA M, MARSHALL A, PETROPOULOS IN, PONIRAKIS G, RUSSELL AW, SAMPSON GP, SHAHIDI AM, SRINIVASAN S, TAVAKOLI M, VAGENAS D, MALIK RA, EFRON N: Longitudinal assessment of neuropathy in type 1 diabetes using novel ophthalmic markers (LANDMark): study design and baseline characteristics. Diabetes Res Clin Pract 104: 248-256, 2014.

QUADRADO MJ, POPPER M, MORGADO AM, MURTA JN, VAN BEST JA: Diabetes and corneal cell densities in humans by in vivo confocal microscopy. Cornea 25: 761-768, 2006.

REICHARD M, HOVAKIMYAN M, GUTHOFF RF, STACHS O: In vivo visualisation of murine corneal nerve fibre regeneration in response to ciliary neurotrophic factor. Exp Eye Res 120: 20-27, 2014.

ROSENBERG ME, TERVO TM, IMMONEN IJ, MULLER LJ, GRONHAGEN-RISKA C, VESALUOMA MH: Corneal structure and sensitivity in type 1 diabetes mellitus. Invest Ophthalmol Vis Sci 41: 2915-2921, 2000.

SHIH KC, LAM KS, TONG L: A systematic review on the impact of diabetes mellitus on the ocular surface. Nutr Diabetes 7: e251, 2017.

SMITH AG, KIM G, PORZIO M, ALLEN B, KOACH M, MIFFLIN M, DIGRE K, KEUNG BM, SINGLETON JR: Corneal confocal microscopy is efficient, well-tolerated, and reproducible. J Peripher Nerv Syst 18: 54-58, 2013.

SONG F, XUE Y, DONG D, LIU J, FU T, XIAO C, WANG H, LIN C, LIU P, ZHONG J, YANG Y, WANG Z, PAN H, CHEN J, LI Y, CAI D, LI Z: Insulin restores an altered corneal epithelium circadian rhythm in mice with streptozotocin-induced type 1 diabetes. Sci Rep 6: 32871, 2016.

SUDHIR RR, RAMAN R, SHARMA T: Changes in the corneal endothelial cell density and morphology in patients with type 2 diabetes mellitus: a population-based study, Sankara Nethralaya Diabetic Retinopathy and Molecular Genetics Study (SN-DREAMS, Report 23). Cornea 31: 1119-1122, 2012.

SZAFLIK JP, KAMINSKA A, UDZIELA M, SZAFLIK J: In vivo confocal microscopy of corneal grafts shortly after penetrating keratoplasty. Eur J Ophthalmol 17: 891-896, 2007. 
SZALAI E, DEAK E, MODIS L JR, NEMETH G, BERTA A, NAGY A, FELSZEGHY E, KAPOSZTA R, MALIK RA, CSUTAK A: Early corneal cellular and nerve fiber pathology in young patients with type 1 diabetes mellitus identified using corneal confocal microscopy. Invest Ophthalmol Vis Sci 57: 853-858, 2016.

TAVAKOLI M, QUATTRINI C, ABBOTT C, KALLINIKOS P, MARSHALL A, FINNIGAN J, MORGAN P, EFRON N, BOULTON AJ, MALIK RA: Corneal confocal microscopy: a novel noninvasive test to diagnose and stratify the severity of human diabetic neuropathy. Diabetes Care 33: 1792-1797, 2010.

TAVAKOLI M, PETROPOULOS IN, MALIK RA: Assessing corneal nerve structure and function in diabetic neuropathy. Clin Exp Optom 95: 338-347, 2012.

TAVAKOLI M, PETROPOULOS IN, MALIK RA: Corneal confocal microscopy to assess diabetic neuropathy: an eye on the foot. J Diabetes Sci Technol 7: 1179-1189, 2013.

TAVAKOLI M, FERDOUSI M, PETROPOULOS IN, MORRIS J, PRITCHARD N, ZHIVOV A, ZIEGLER D, PACAUD D, ROMANCHUK K, PERKINS BA, LOVBLOM LE, BRIL V, SINGLETON JR, SMITH G, BOULTON AJ, EFRON N, MALIK RA: Normative values for corneal nerve morphology assessed using corneal confocal microscopy: a multinational normative data set. Diabetes Care 38: 838-843, 2015.

THREATT J, WILLIAMSON JF, HUYNH K, DAVIS RM: Ocular disease, knowledge and technology applications in patients with diabetes. Am J Med Sci 345: 266-270, 2013.

UTSUNOMIYA T, NAGAOKA T, HANADA K, OMAE T, YOKOTA H, ABIKO A, HANEDA M, YOSHIDA A: Imaging of the corneal subbasal whorl-like nerve plexus: more accurate depiction of the extent of corneal nerve damage in patients with diabetes. Invest Ophthalmol Vis Sci 56: 5417-5423, 2015.

VANATHI M, TANDON R, SHARMA N, TITIYAL JS, PANDEY RM, VAJPAYEE RB: In-vivo slit scanning confocal microscopy of normal corneas in Indian eyes. Indian J Ophthalmol 51: 225-230, 2003.

VILLANI E, BAUDOUIN C, EFRON N, HAMRAH P, KOJIMA T, PATEL SV, PFLUGFELDER SC, ZHIVOV A, DOGRU M: In vivo confocal microscopy of the ocular surface: from bench to bedside. Curr Eye Res 39: 213-231, 2014.

WANG EF, MISRA SL, PATEL DV: In vivo confocal microscopy of the human cornea in the assessment of peripheral neuropathy and systemic diseases. Biomed Res Int 95: 1081, 2015.

WILKINSON CP, FERRIS FL 3RD, KLEIN RE, LEE PP, AGARDH CD, DAVIS M, DILLS D, KAMPIK A, PARARAJASEGARAM R, VERDAGUER JT: Proposed international clinical diabetic retinopathy and diabetic macular edema disease severity scales. Ophthalmology 110: 1677-1682, 2003.

WU YC, BUCKNER BR, ZHU M, CAVANAGH HD, ROBERTSON DM: Elevated IGFBP3 levels in diabetic tears: a negative regulator of IGF-1 signaling in the corneal epithelium. Ocul Surf 10: 100-107, 2012.

ZHIVOV A, WINTER K, HOVAKIMYAN M, PESCHEL S, HARDER V, SCHOBER HC, KUNDT G, BALTRUSCH S, GUTHOFF RF, STACHS O: Imaging and quantification of subbasal nerve plexus in healthy volunteers and diabetic patients with or without retinopathy. PLoS One 8: e52157, 2013.

ZOCHODNE DW: Diabetes and the plasticity of sensory neurons. Neurosci Lett 596: 60-65, 2015. 